\title{
Perioperative fluid and volume management: physiological basis, tools and strategies
}

\author{
Mike S Strunden ${ }^{1,2^{*}}$, Kai Heckel ${ }^{1,2}$, Alwin E Goetz ${ }^{1,2}$, Daniel A Reuter ${ }^{1,2}$
}

\begin{abstract}
Fluid and volume therapy is an important cornerstone of treating critically ill patients in the intensive care unit and in the operating room. New findings concerning the vascular barrier, its physiological functions, and its role regarding vascular leakage have lead to a new view of fluid and volume administration. Avoiding hypervolemia, as well as hypovolemia, plays a pivotal role when treating patients both perioperatively and in the intensive care unit. The various studies comparing restrictive vs. liberal fluid and volume management are not directly comparable, do not differ (in most instances) between colloid and crystalloid administration, and mostly do not refer to the vascular barrier's physiologic basis. In addition, very few studies have analyzed the use of advanced hemodynamic monitoring for volume management.

This article summarizes the current literature on the relevant physiology of the endothelial surface layer, discusses fluid shifting, reviews available research on fluid management strategies and the commonly used fluids, and identifies suitable variables for hemodynamic monitoring and their goal-directed use.
\end{abstract}

\section{Introduction}

There is increasing evidence that fluid management influences patient's outcome as well in critical illness, as during and after major surgery. Hence, the numerous different aspects contributing to fluid management have been in the focus of both basic and clinical research during the past years. Basically three questions are intrinsically tied to fluid administration perioperatively and in critically ill patients: 1) What happens to intravascular fluid in health and disease? 2) How do different intravenous fluids behave after application? 3) What are the goals for volume administration and how can they be assessed and reached? Current basic research brought fascinating insights of the function of the endothelial vascular barrier and, in particular, regarding functional changes that lead to vascular leakage. Experimental and clinical trials investigating the effects of both crystalloid and colloid solutions-and their natural and artificial representatives-have shown quite conflicting results. The same accounts for the mainly clinical studies that primarily focussed on clinical goals to guide

\footnotetext{
* Correspondence: m.strunden@uke.de

${ }^{1}$ Center of Anesthesiology and Intensive Care Medicine, Department of Anesthesiology, Hamburg-Eppendorf University Medical Center Martinistraße 52, 20246 Hamburg, Germany.

Full list of author information is available at the end of the article
}

perioperative volume therapy. However, all of those three aspects cannot be separated from each other when defining rational strategies for fluid management. Thus, this review article summarizes the knowledge of the function and dysfunction of the endothelial vascular barrier, on the effect of different intravenous fluids and on the opportunities of hemodynamic monitoring to enable drawing conclusions for rational concepts of perioperative fluid and volume management.

\section{The underlying aspects}

The physiologic basis: why does fluid stay within the vasculature?

Two thirds of human body fluid is located in the intracellular compartment. The remaining extracellular space is divided into blood plasma and interstitial space. Both compartments communicate across the vascular barrier to enable exchange of electrolytes and nutriments as the basis for cell metabolism. The positive intravascular pressure continuously forces blood toward the interstitial space. Under physiologic conditions, large molecules, such as proteins and colloids, cannot cross the barrier in relevant amounts, which is a necessity for the regular function of circulation. Otherwise, the intravascular hydrostatic pressure would lead to uncontrollable loss of fluid toward the interstitial space and disseminated

\section{SpringerOpen $^{\odot}$}


tissue edema [1]. In 1896, Ernest Starling suggested an interstitial colloid osmotic pressure far below the intravascular pressure. The concentration gradient across the vascular barrier generates a flow, which is directed into the vasculature and opposes the hydrostatic pressure resulting in an only low filtration per unit of time. According to the Starling principle, only the endothelial cell line is responsible for the vascular barrier function [1]. In a rat microvessel model, it has been shown that the interstitial colloid osmotic pressure was nearly $70 \%$ to intravascular osmotic pressure without causing interstitial edema, which is in contrast to the Starling's concept, suggesting an only minor role for the interstitial protein concentration [2]. The endothelial glycocalyx plays a pivotal role in this context. Every healthy vascular endothelium is coated by transmembrane syndecans and membrane-bound glypicans containing heparan sulfate and chondroitin sulfate side chains, which together constitute the endothelial glycocalyx [3,4]. Bound plasma proteins, solubilized glycosaminoglycans, and hyaluronan are loading the glycocalyx to the endothelial surface layer (ESL), which is subject of a periodic constitution and degradation. Under physiologic conditions, the ESL has a thickness of approximately $1 \mu \mathrm{m}$ and binds approximately $800 \mathrm{ml}$ of blood plasma, so plasma volume can be divided into a circulating and noncirculating part $[4,5]$. Accordingly, the glycocalyx seems to act as a molecular filter, retaining proteins and increasing the oncotic pressure within the endothelial surface layer. A small space between the anatomical vessel wall and the ESL remains nearly protein-free [2]. Thus, fluid loss across the vascular barrier is limited by an oncotic pressure gradient within the ESL [6]! Starlings' classic principle was therefore modified to the "double-barrierconcept" in which not only the endothelial cell line but primarily the endothelial surface layer constitutes the vascular barrier [6].

\section{Vascular barrier dysfunction: reasons and consequences}

The ESL constitutes the first contact surface between blood and tissue and is involved in many processes beside vascular barrier function, such as inflammation and the coagulation system. A number of studies identified various agents and pathologic states impairing the glycocalyx scaffolding and ESL thickness. In a genuine pig heart model, Chappell et al. demonstrated a 30-fold increased shedding of heparan sulphate after postischemic reperfusion [7]. These data were approved by a clinical investigation, which showed increased plasma levels of syndecan-1 and heparan sulphate in patients with global or regional ischemia who underwent major vascular surgery [8]. Beside ischemia/reperfusion-injury, several circulating mediators are known to initiate glycocalyx degradation. Tumor necrosis factor- $(\alpha)$, cytokines, proteases, and heparanase from activated mast cells are well-described actors in systemic inflammatory response syndrome leading to reduction of the ESL thickness, which triggers increased leucocyte adhesion and transendothelial permeability $[7,9,10]$. Interestingly, hypervolemia also may cause glycocalyx impairment mediated by liberation of atrial natriuretic peptide [11]. Hypervolemia resulting from inadequately high fluid administration therefore may cause iatrogenic glycocalyx damage. As shown in basic research, the dramatic consequence of a rudimentary glycocalyx, which loses much of its ability to act as a second barrier, is strongly increased transendothelial permeability and following formation of interstitial edema $[7,11]$. The relevance of these experimental data were impressively underlined by Nelson et al., who found increased plasma levels of glycosaminoglycans and syndecan-1 in septic patients, whereas median glycosaminoglycan levels were higher in patients who did not survive [12].

\section{Fluid balance: where does fluid get lost?}

Urine production and insensible perspiration are physiologically replaced by free water absorbed from the gastrointestinal system and primarily affect the extravascular space, if they are not pathologically increased. Because the physiologic replacement is limited in fasted patients, it has to be compensated artificially by infusing crystalloids. The composition of the used infusion should be similar to the physiologic conditions to avoid acid-base disorders, which mostly accounts for balanced crystalloid infusions. During surgery, trauma or septic shock additional fluid loss (blood loss, vascular leakage) affects mainly the intravascular compartment $[13,14]$. Consequently, the first type of fluid loss is attenuated by redistribution between intracellular, interstitial, and intravascular space slowly and causes dehydration, whereas the second type of loss leads to acute hypovolemia. Preoperative hypovolemia after an overnight fasting period, as described in anesthesia text books $[15,16]$, cannot be explained by the considerations above and does not occur regularly in all patients [17]. Fluid reloading is unjustified, at least in cardiovascular healthy patients before low-invasive surgery [17]. Mediated by increased liberation of atrial natriuretic peptide, undifferentiated fluid loading can cause glycocalyx degradation, increase vascular permeability, promote tissue edema formation and therefore may constitute a starting point of the vicious circle of vascular leakage and organ failure $[11,18]$. Fluid loss from insensible perspiration also is obviously overestimated in many patients, although loss of only $1 \mathrm{ml} / \mathrm{kg}$ per hour occurs even when the abdominal cave is opened [19]. In theory, it should be adequate to substitute only the losses described earlier to maintain a normal blood volume in the critically ill patient. Based 
on the assumption that a generous fluid administration could prevent hypotension and postoperative renal failure, frequently much greater amounts are infused perioperatively [20], although there is no evidence that the incidence of renal failure is decreased by a liberal infusion regimen during surgery [21]. Furthermore, prophylactic crystalloid infusion does not influence the occurrence of hypotension caused by vessel dilatation [22]. Nevertheless, patients require much more intravenous fluids than suggested by physiologic considerations. Shown by blood volume measurements, major surgery causes a deficit of 3-6 liters in the perioperative fluid balance $[23,24]$. The peak even persists up to 72 hours after trauma or surgery [25]. The common explanation for this phenomenon is a fluid shift into the so-called third space. This third space can be divided into an "anatomic" and a "nonanatomic" part. Physiologic fluid shifting from the vessel toward the interstitial space across an intact vascular barrier contains only small amounts of proteins. It does not cause interstitial edema as long as it can be quantitatively managed by the lymphatic system. Losses into the "anatomic" third space are based on this mechanism but in a pathologic quantity $[13,14]$, which transgresses the capacity of the lymphatic system. The nonanatomic third space, in contrast, is believed to be a compartment separated from the interstitial space $[13,14]$. Losses toward this compartment are assumed to be trapped and lost for extracellular exchange. Cited examples for nonanatomic third space losses are fluid accumulation in traumatized tissue, bowel, or peritoneal cavity $[15,16]$, but despite intensive research, such a space has never been identified! Fluid is shifted from the intravascular to the interstitial space! This fluid shift can be classified into two types [13]:

Type 1, occurring always and even if the vascular barrier is intact, represents the physiologic, almost proteinfree shift out of the vasculature. Occasionally it emerges at pathologic amounts.

Type 2, the pathologic shift is caused by dysfunction of the vascular barrier. In contrast to type 1, fluid crossing the barrier contains proteins close to plasma concentration [13]. This shift has basically three reasons. First, surgical manipulation increases capillary protein permeability excessively [26]. Interstitial fluid raised approximately $10 \%$ during realization of an enteral anastomosis in a rabbit without any fluids being infused [27]. Concomitant administration of $5 \mathrm{ml} / \mathrm{kg}$ of crystalloid infusion even doubled this edema. Second, reperfusion injury and inflammatory mediators compromise the vascular barrier [7-10]. Third, iatrogenic hypervolemia can lead to glycocalyx degradation and cause an extensive shift of fluid and proteins toward the tissue $[23,24]$. The pathologic shift affects all intravenous fluids. Opposed to the common believe that, in contrast to crystalloids, colloids would stay within the vasculature, Rehm et al. described a volume-effect $>90 \%$ only when a tetrastarch solution was infused titrated to the actual intravascular volume loss. Administered as a bolus in a normovolemic patient, two thirds of the infused volume left the vasculature immediately $[23,24]$. Volume resuscitation with colloids obviously requires careful titration to current losses to avoid a remarkable protein shift toward the interstitial space [14]. Based on the double-barrier concept, hypoproteinemia even intensifies a vascular barrier dysfunction and promotes tissue edema formation. Perioperative fluid shifting is reflected in clinical data published two decades ago. Lowell et al. showed a weight gain of more than $10 \%$ in $>40 \%$ of patients admitted to the intensive care unit after major surgery. This increase of body weight, representing interstitial edema, correlated strongly with mortality [28].

\section{Dehydration or hypovolemia?}

Dehydration, affecting primarily the extravascular compartment, and acute hypovolemia are two different diagnoses and deserve different therapeutic considerations. Urine production and insensible perspiration cause a loss of colloid-free fluid, which, due to redistribution between intravascular and extravascular space, does normally not impair the intravascular compartment directly. Thus, the resulting dehydration has to be treated by refilling the extravascular space and replacing further losses by crystalloid administration [13]. In contrast, acute hypovolemia at first affects the intravascular compartment. Because crystalloids distribute freely between interstitial and intravascular space, they are not suitable for volume resuscitation in acute hypovolemia. Lost colloids and proteins cause a decreased intravascular oncotic pressure, which would be aggravated by administration of colloid-free intravenous fluid and would enforce the formation of interstitial edema. Thus, fluids that mainly remain within the vasculature and maintain oncotic pressure are needed to treat acute loss of plasma volume effectively: colloids.

\section{Intravenous fluids: crystalloids and colloids Crystalloids}

Crystalloids freely distribute across the vascular barrier. Only one fifth of the intravenously infused amount remains intravascularly $[15,16]$. Proclaimed by textbooks, a fourfold amount of crystalloid infusion is needed to reach comparable volume effects as achieved with colloid administration. Whereas this is true if the vascular barrier is intact, in patients suffering from capillary leakage ratios from only 1.6:1 to $1: 1$ (crystalloid to colloid infusion) were observed to reach equivalent effects $[29,30]$. Nevertheless, colloid treatment resulted in a greater linear increase in cardiac preload 
and output in septic and nonseptic hypovolemic patients compared with crystalloid administration [31], and its volume expansion lasted longer during acute hemorrhage experimentally [32]. Although currently discussed, regarding the double-barrier concept one could assume that colloids distribute nearly as freely as crystalloids across a seriously impaired vascular barrier. However, volume resuscitation with crystalloid infusions was associated with serious complications, such as respiratory distress syndrome, cerebral edema, and abdominal compartment syndrome in patients with major trauma [33-35] and promotes the development of hyperchloremic acidosis [36]. Even if there is ongoing discussion about the benefits and risks of balanced crystalloid solutions, their use is beneficial to avoid acid-base disorders [25].

\section{Colloids}

The only natural colloid used in clinical matters is albumin. The artificial colloids hydroxyethyl starch (HES) and gelatin are used prevalently in European countries, whereas albumin is applied less commonly [37].

\section{Albumin}

Under physiologic conditions, albumin is the molecule mainly accountable for intravascular osmotic pressure and should be an ideal colloid to restore protein loss from the vasculature. However, as a natural colloid, albumin may cause severe allergic reaction and immunologic complications. Current date concerning albumin use to treat hypovolemia mainly originate from critically ill patients. A Cochrane review of 30 randomized, controlled trials, including 1,419 patients with hypovolemia, showed no evidence for a reduced mortality comparing albumin to crystalloid volume resuscitation. Usage of albumin may contrariwise even increase mortality [38]. More recently, the SAFE Study, including 6,997 patients and comparing albumin to normal saline fluid resuscitation, found neither beneficial effects nor an increased mortality in the albumin group. Additionally, no differences in days of mechanical ventilation or need for renal-replacement therapy were observed [39]. In contrast to isooncotic albumin, which does not influence the outcome of critically ill patients, treatment with hyperoncotic albumin increased mortality [40]. Therefore, administration of isooncotic albumin may be justifiable in particular cases but not as a routine strategy for volume resuscitation.

\section{Gelatins}

Gelatins are polydispersed polypeptides from degraded bovine collagen. The average molecular weight of gelatin solutions is 30,000 to $35,000 \mathrm{Da}$ and their volumeexpanding power is comparable. Several studies have examined the pharmacological safety of gelatins. In brief, all preparations are said to be safe in regard to coagulation and organ integrity $[15,16]$ except kidney function. Mahmood et al. demonstrated higher levels of serum urea and creatinine as a more distinct tubular damage in patients treated with $4 \%$ gelatin solution compared with hydroxyethyl starch (HES) solutions while undergoing aortic aneurysm surgery [41]. Therefore, use of gelatins is limited in renal-impaired patients.

\section{Hydroxyethyl starch}

Hydroxyethyl starch, an artificial polymer, is derived from amylopectin, which is a highly branched chain of glucose molecules obtained from waxy maize or potatoes. Conservation from degradation and water solubility are achieved by hydroxyethylation of the glucose units. HES solutions are available in several preparations and vary in concentration, molecular weight, molar substitution, $C^{2} / C^{2}$ ratio, solvent, and pharmacologic profile. Although small HES molecules $(<50-60 \mathrm{kD})$ are eliminated rapidly by glomerular filtration, larger molecules are hydrolyzed to smaller fractions and are partially taken up in the reticuloendothelial system. Although this storage seems not to impair the mononuclear phagocytic system, it is remarkable that low molecular weight HES accumulates less compared with high molecular weight HES [42]. Negative effects of high molecular HES on the coagulation system are well described. Preparations $>200 \mathrm{kD}$ lead to a reduction of von Willebrand factor and factor VIII, causing a decreased platelet adhesion. Low molecular weight preparations, such as HES 130/0.4, have only minimal effects on coagulation. HES in balanced solution increases the expression of activated platelet GP IIb/IIIa, indicating an improved hemostasis [43,44]. Focusing on kidney function, an $80 \%$ rate of "osmotic nephrosis-like lesions" and impaired renal function were reported in kidney transplant recipients after administration of HES 200/0.62 to brain-dead organ donors $[45,46]$. In septic patients, usage of $10 \%$ HES 200/0.5 correlated with a higher incidence of renal failure compared with crystalloids [47]. Admittedly, HES was administered without regard to exclusion criteria and dose limitations in this study. The most likely pathomechanism of renal impairment by colloids is the induction of urine hyperviscosity by infusing hyperoncotic agents in dehydrated patients. Glomerular filtration of hyperoncotic molecules causes a hyperviscous urine and results in stasis of the tubular flow [48]. Elevated plasma oncotic pressure, regardless of which genesis, is known to cause acute renal failure since more than 20 years [49]. Based on this pathogenesis, all hyperoncotic colloids may induce renal damage, whereas iso-oncotic tetra starch solutions, such as 6\% HES 130/0.4, seem 
not to impair renal function $[41,46]$. After administration of extremely high application rates (up to 66 liters in 21 days) in patients with severe head injury, no impairment of renal function was observed [50]. In contrast to results of the VISEP study [47], the SOAP study, which included more than 3,000 critically ill septic patients treated with pentastarch and tetrastarch solutions, also showed no higher risk for renal failure [51]. Hydroxyethyl starch was administered in much lower amounts (13 vs. $70 \mathrm{ml} / \mathrm{kg}$ ) and for a shorter period in the SOAP study. There is evidence that HES also modulates inflammation. Synthetic colloids inhibit neutrophil adhesion to the endothelium and neutrophil infiltration of the lung $[52,53]$.

Furthermore, HES attenuated inflammatory response in septic rats as well as in rats volume resuscitated with HES 130/0.4 during severe hemorrhagic shock by decreasing tumor necrosis factor-alpha, interleukins, and oxidative stress $[53,54]$. Although advantageous aspects of volume replacement with so-called "modern" isooncotic tetrastarch solutions, in particular in reaching early hemodynamic stability are comprehensible [31,32], data on focussed, adequately powered, prospective clinical trials proving their outcome-relevance are needed.

\section{Goals and strategies for volume replacement}

Because the primary goal of the cardiovascular system is to supply adequate amounts of oxygen to the body and to match its metabolic demands, the target of volume management is to maintain adequate tissue perfusion to ensure tissue oxygenation. Hypovolemia, as well as hypervolemia, decreases tissue perfusion and may result in organ failure [55-59]. Even supplemental oxygen does not improve oxygenation in hypoperfused tissue [60]. Because hypovolemia is a frequent cause for hemodynamic deterioration in critically ill patients, securing an adequate intravascular volume is a cornerstone of hemodynamic management. But how can we assess "adequate" intravascular volume? Because the relation between hemodynamic variables is complex in health already, it is even more complex in disease and their interpretation requires a solid understanding of cardiovascular regulation mechanism.

In hemodynamic unstable patients, basically four functional questions need to be answered. Because the primary goal of resuscitation is to secure tissue oxygenation, the first question is already the most decisive, but also the most difficult one: Is tissue oxygenation adequate? Because representative tissue oxygenation is not measurable directly, primarily three variables are used as surrogates: mixed venous oxygen saturation; central venous oxygenation; and serum lactate. Use, interpretation, and significance of these parameters concerning assessment of tissue oxygenation are discussed elsewhere. In brief, none of them is able to detect tissue oxygen debt definitely, because every single one is influenced by various morbidities and drug interactions [61-64]. The second question is: How can cardiac output $(\mathrm{CO})$, as the main determinate of oxygen delivery, be improved? Or, better representing clinical matters: Is the patient volume responsive? The third question regards the vasomotor tone: Is it increased, decreased, or normal in the hypotensive patient? Fourth, heart work: Is the heart able to sustain an adequate $\mathrm{CO}$ when arterial pressure is restored without going into failure [65]?

Usually physicians address these questions by measuring mean arterial pressure (MAP), central venous pressure (CVP), and by observing diuresis [66]. All of these parameters are easy to measure, but actually do not allow to assess hemodynamic instability sufficiently or to differentiate its cause adequately. If disease leads to a decrease of $\mathrm{CO}$, the physiologic reaction of the body, mediated by baroreceptors, is to restore the likewise decreased arterial pressure to maintain cerebral perfusion pressure [67]. This is frequently accompanied by tachycardia, caused by modulation of the sympathetic tone. Hence, hypotension reflects the failure of this compensating mechanism, whereas normotension does not automatically ensure hemodynamic stability [68]. In addition, tachycardia and hypotension can be absent during hypovolaemic shock until intravascular volume loss reaches $20 \%$ or more $[69,70]$. CVP shows a poor correlation to blood volume [71], is inadequate to detect hypovolemia reliably, and most notably cannot sense a decreased cardiac output and tissue oxygen debt in an early state. Furthermore, changes in CVP after volume administration do not allow any conclusions to changes in stroke volume (SV) or cardiac output (CO) [72]. Measuring CVP is therefore inadequate to assess the patient's hemodynamics and to manage volume resuscitation. Because $\mathrm{CO}$ is the primary determinate by which oxygen donation to the tissue is varied to match metabolic requirements, the effectiveness of a resuscitation therapy can be evaluated best by continuous monitoring of cardiac output. Several different methods, ranging from the classical indicator dilution techniques to less invasive approaches, such as arterial pulse contour analysis and Doppler techniques, are clinically available. A detailed description and discussion of their individual advantages and disadvantages is beyond the scope of this article and can be found in recent reviews [73,74]. Suitable monitoring techniques for defining treatment strategies are able to assess cardiac output as well as cardiac preload and, first of all, to predict volume responsiveness of the patient, which mostly applies to volumetric and functional parameters utilizing the 
heart-lung interaction under mechanical ventilation [75-78]. In the past, various studies were published that favored individual concepts of perioperative volume management strategies. Most of them originated from perioperative care and focussed primarily on the treatment in the operating room. Of course, those strategies impact postoperative ICU treatment as well. "Restrictive" strategies were compared with "permissive" or "liberal" ones. However, commonly accepted definitions of "restrictive" or "liberal" fluid strategies do not exist, making those studies nearly incomparable. Investigators normally labelled their traditional standard fluid regimen the "standard" group and compared it with their own restrictive fluid administration model. "Liberal" in one study was already "restrictive" in the other trial and fluid administration followed rigid schemas or different goals. Additionally, endpoints of the given studies varied from postoperative vomiting, pain, or tissue oxygenation to bowel recovery time, which de facto rules out a comparison [79-82]. One of the most cited studies in this regard is the work of Brandstrup et al., who demonstrated that perioperative fluid restriction (2740 vs. $5388 \mathrm{ml}$ ) reduced the incidence of anastomotic leakage, pulmonary edema, pneumonia, and wound infection in 141 patients undergoing major colorectal surgery without increasing renal failure rate. Interestingly, a closer look at the infusion protocol reveals a comparison between crystalloid versus colloid fluid administration. The restrictive group received mainly colloids, whereas the liberal group was treated exclusively with crystalloids [79]. All of those studies have in common that no hemodynamic goals were set, which is in contrast to the "goal-directed-therapy (GDT) approach" known most prominently from the study by Rivers et al., in which the authors used central venous pressure, mean arterial pressure, serum lactate, and mixed venous oxygen saturation as goals to optimize the early treatment in septic patients [83]. Further peri- and postoperative studies in surgical patients underline the importance of "functional" hemodynamic goals to improve patients' outcome. In a meta-analysis encasing four prospective randomized trials, cardiac output guided fluid management reduced hospital stay and lessened complication rate [84]. Additionally, interleukin- 6 response was attenuated in a colorectal surgery study using a Doppler-optimized goal-directed fluid management [85]. Göpfert et al. reported a reduced time of mechanical ventilation and intensive care unit stay in cardiac surgery patients using the global end-diastolic volume index and cardiac output to manage volume administration [86]. The extravascular lung water index may be a useful tool for GDT, too, and is subject of current discussion
[87]. Furthermore, goal-directed fluid therapy reduces inflammation, morbidity, and mortality not only in severe sepsis and septic shock, but also in patients who undergo major surgery [88-90].

\section{Conclusions}

Consolidated findings regarding the endothelial surface layer led to a new comprehension of the vascular barrier. Starlings' principle was adjusted to the "double-barrier concept" and the mechanisms of ESL alteration in critically ill patients seem to play a major role in tissue edema formation. Because glycocalyx diminution leads to an increased capillary permeability, fluid loss toward the interstitial space, commonly considered to be a loss toward the "third space," is one major consequence of ESL degradation. Studies concerning fluid and volume therapy prove an adverse effect of tissue edema formation on organ function and mortality. Therefore, knowledge of the consequences of infusing different types of crystalloids and colloids during physiologic and pathologic states is necessary. Furthermore, fluid and volume administration are two different therapies for two different diagnoses. Dehydration resulting from urine loss, preoperative fasting, and insensible perspiration requires fluid administration primarily based on crystalloid infusions. Intravascular volume deficit, i.e., acute hypovolemia, resulting in a decreased cardiac output requires volume replacement, where colloid administration appears meaningful, although current clinical data are not finally consistent. The right amount of administered volume should be titrated "goal directed" using a strategy based on macro-hemodynamic parameters of flow and volume.

\section{Author details}

${ }^{1}$ Center of Anesthesiology and Intensive Care Medicine, Department of Anesthesiology, Hamburg-Eppendorf University Medical Center Martinistraße 52, 20246 Hamburg, Germany. ${ }^{2}$ Cardiovascular Research Center, HamburgEppendorf University Medical Center Martinistraße 52, 20246 Hamburg, Germany.

\section{Authors' contributions}

$\mathrm{MS}, \mathrm{KH}, \mathrm{AG}$ and DR enquired the literature and drafted the manuscript. All authors read and approved the final manuscript.

\section{Competing interests}

Daniel A. Reuter is member of the medical advisory board of Pulsion Medical Systems AG and held lectures for B. Braun Melsungen AG and Fresenius Kabi. Alwin E. Goetz is member of the medical advisory board of Pulsion Medical Systems AG, Germany, and held lectures for B. Braun

Melsungen AG, Fresenius Kabi, Baxter, and Abbott.

Received: 1 February 2011 Accepted: 21 March 2011

Published: 21 March 2011

\section{References}

1. Starling E: On the absorption of fluid the connective tissue spaces. J Physiol 1896, 19:312-26.

2. Adamson RH, Lenz JF, Zhang X, Adamson GN, Weinbaum S, Curry FE: Oncotic pressures opposing filtration across non-fenestrated rat microvessels. J Physiol 2004, 557:889-907. 
3. Pries AR, Kuebler WM: Normal endothelium. Handb Exp Pharmacol 2006, 1:1-40.

4. Pries AR, Secomb TW, Gaehtgens P: The endothelial surface layer. Pfluger Arch 2002, 440:653-66.

5. Rehm M, Haller M, Orth V, Kreimeier U, Jacob M, Dressel H, Mayer S Brechtelsbauer $\mathrm{H}$, Finsterer $\mathrm{U}$ : Changes in blood volume and hematocrit during acute preoperative volume loading with $5 \%$ albumin or $6 \%$ hetastarch solutions in patients before radical Hysterectomy. Anesthesiology 2001, 95:849-56.

6. Rehm M, Zahler S, Lötsch M, Welsch U, Conzen P, Jacob M, Becker BF Endothelial glycocalyx as an additional barrier determining extravasation of $6 \%$ hydroxyethyl starch or $5 \%$ albumin solutions in the coronary vascular bed. Anesthesiology 2004, 100:1211-23.

7. Chappell D, Jacob M, Hofmann-Kiefer K, Bruegger D, Rehm M, Conzen P, Welsch U, Becker BF: Hydrocortisone preserves the vascular barrier by protecting the endothelial glycocalyx. Anesthesiology 2007, 107:776-84.

8. Rehm M, Bruegger D, Christ F, Conzen P, Thiel M, Jacob M, Chappell D, Stoeckelhuber M, Welsch U, Reichart B, Peter K, Becker BF: Shedding of the endothelial glycocalyx in patients undergoing major vascular surgery with global and regional ischemia. Circulation 2007, 116:1896-906.

9. Chappell D, Westphal M, Jacob M: The impact of the glycocalyx on microcirculatory oxygen distribution in critical illness. Curr Opin Anaesthesiol 2009, 22:155-62.

10. Bernfield M, Gotte M, Park PW, Reizes O, Fitzgerald ML, Lincecum J, Zako M: Functions of cell surface heparan sulfate proteoglycans. Annu Rev Biochem 1999, 68:729-77.

11. Bruegger $\mathrm{D}$, Jacob M, Rehm M, Loetsch M, Welsch U, Conzen P, Becker BF: Atrial natriuretic peptide induces shedding of endothelial glycocalyx in coronary vascular bed of guinea pig hearts. Am J Physiol Heart Circ Physiol 2005, 289:H1993-9.

12. Nelson A, Berkestedt I, Schmidtchen A, Ljunggren L, Bodelsson M: Increased levels of glycosaminoglycans during septic shock: relation to mortality and the antibacterial actions of plasma. Shock 2008, 30:623-7.

13. Chappell D, Jacob M, Hofmann-Kiefer K, Conzen P, Rehm M: A Rational approach to perioperative fluid management. Anesthesiology 2008, 109:723-40.

14. Chappell D, Jacob M, Becker BF, Hofmann-Kiefer K, Conzen P, Rehm M: Expedition glycocalyx. A newly discovered "Great Barrier Reef.". Anaesthesist 2008, 57:959-69.

15. Larsen R: Anästhesie. München: Urban \& Fischer Elsevier GmbH; 2008

16. Rossaint R, Werner C, Zwißler B: Die Anästhesiologie. Heidelberg: Springer Medizin Verlag; 2008

17. Jacob M, Chappell D, Conzen P, Finsterer U, Rehm M: Blood volume is normal after preoperative overnight fasting. Acta Anaesthesiol Scand 2008, 52:522-9.

18. Kamp-Jensen M, Olesen $\mathrm{KL}$, Bach V, Schütten HJ, Engquist $A$ : Changes in serum electrolyte and atrial natriuretic peptide concentrations, acid-base and haemodynamic status after rapid infusion of isotonic saline and Ringer lactate solution in healthy volunteers. Br J Anaest 1990, 64:606-10.

19. Lamke LO, Nilsson GE, Reithner HL: Water loss by evaporation from the abdominal cavity during surgery. Acta Chir Scand 1977, 413:279-84.

20. Sear JW: Kidney dysfunction in the postoperative period. $\mathrm{Br} J$ Anaesth 2005, 95:20-32

21. Desborough JP: The stress response to trauma and surgery. $\mathrm{Br} J$ Anaesth 2000, 85:109-17.

22. Jackson $\mathrm{R}$, Reid JA, Thorburn J: Volume preloading is not essential to prevent spinal-induced hypotension at caesarean section. $\mathrm{Br} J$ Anaesth 1995, 75:262-5.

23. Rehm M, Orth V, Kreimeier U, Thiel M, Mayer S, Brechtelsbauer $H$ Finsterer U: Changes in blood volume during acute normovolemic hemodilution with $5 \%$ albumin or $6 \%$ hydroxyethylstarch and intraoperative retransfusion. Anaesthesist 2001, 50:569-79.

24. Rehm M, Orth $V$, Kreimeier U, Thiel M, Haller M, Brechtelsbauer $\mathrm{H}$ Finsterer U: Changes in intravascular volume during acute normovolemic hemodilution and intraoperative retransfusion in patients with radical hysterectomy. Anesthesiology 2000, 92:657-64.

25. Robarts WM: Nature of the disturbance in the body fluid compartments during and after surgical operations. $\mathrm{Br}$ J Surg 1979, 66:691-5.

26. Landis EM: Heteroposity of the capillary wall as indicated by cinematographic analysis of the passage of dyes. Ann N Y Acad Sci 1964, 116:765-73.
27. Chan ST, Kapadia CR, Johnson AW, Radcliffe AG, Dudley HA: Extracellular fluid volume expansion and third space sequestration at the site of small bowel anastomoses. Br J Surg 1983, 70:36-9.

28. Lowell JA, Schifferdecker C, Driscoll DF, Benotti PN, Bistrian BR: Postoperative fluid overload: not a benign problem. Crit Care Med 1990, 18:728-33.

29. Finfer S, Bellomo R, Boyce N, French J, Myburgh J, Norton R: A comparison of albumin and saline for fluid resuscitation in the intensive care unit. $N$ Engl J Med 2004, 350:2247-56.

30. Upadhyay M, Singhi S, Murlidharan J, Kaur N, Majumdar S: Ranomized evaluation of fluid resuscitation with crystalloid (saline) and colloid (polymer from degraded gelatin in saline) in pediatric septic shock. Indian Pediatr 2005, 42:223-31.

31. Trof RJ, Sukul SP, Twisk JW, Girbes AR, Groeneveld AB: Greater cardiac response of colloid than saline fluid loading in septic and non-septic critically ill patients with clinical hypovolemia. Intensive Care Med 2010 36:697-701.

32. Fischer SR, Burnet M, Traber DL, Prough DS, Kramer GC: Plasma volume expansion with solutions of hemoglobin, albumin, and Ringer lactate in sheep. Am J Physiol 1999, 276:H2194-203.

33. Feinstein AJ, Patel MB, Sanui M, Cohn SM, Majetschak M, Proctor KG: Resuscitaion with pressors after traumatic brain injury. J Am Coll Surg 2005, 201:536-45.

34. Wiedemann HP, Wheeler AP, Bernard GR, Thompson BT, Hayden D, deBoisblanc B, Connors AF Jr, Hite RD, Harabin AL: Comparison of two fluid-management strategies in acute lung injury. N Engl J Med 2006, 354:2564-75

35. O'Mara MS, Slater H, Goldfarb IW, Caushaj PF: A prospective, randomized evaluation of intra-abdominal pressures with crystalloid and colloid resuscitation in burn patients. J Trauma 2005, 58:1011-8.

36. Waters JH, Gottlieb A, Schoenwald P, Popovich MJ, Sprung J, Nelson DR Normal saline versus lactated Ringer's solution for intraoperative fluid management in patients undergoing abdominal aortic aneurysm repair: an outcome study. Anesth Analg 2001, 93:817-22.

37. Sakr Y, Payen D, Reinhart K, Sipmann FS, Zavala E, Bewley J, Marx G, Vincent JL: Effects of hydroxyethyl starch administration on renal function in critically ill patients. Br J Anaesth 2007, 98:216-24.

38. Cochrane Injuries Group: Human albumin administration in critically ill patients: systematic review of randomised controlled trials. Cochrane Injuries Group Albumin Reviewers. BJM 1998, 317:235-40.

39. The SAFE Study Investigators: A comparison of albumin and saline for fluid resuscitation in the intensive care unit. N Engl J Med 2004 350:2247-56

40. Schortgen F, Girou E, Deye N, Brochard L, GRYCO Study Group: The risk associated with hyperoncotic colloids in patients with shock. Intensive Care Med 2008, 34:2157-68

41. Mahmood A, Gosling P, Vohra RK: Randomized clinical trial comparing the effects on renal function of hydroxyethyl starch or gelatin during aortic aneurysm surgery. Br J Surg 2007, 94:427-33.

42. Jungheinrich C, Scharpf R, Wargenau M, Bepperling F, Baron JF: The pharmacokinetics and tolerability of an intravenous infusion of the new hydroxyethyl starch $130 / 0.4(6 \%, 500 \mathrm{~mL})$ in mild-to-severe renal impairment. Anesth Analg 2002, 95:544-51.

43. Franz A, Braünlich P, Gamsjäger T, Felfernig M, Gustorff B, KozekLangenecker SA: The effects of hydroxyethyl starches of varying molecular weights on platelet function. Anesth Analg 2001, 92:1402-7.

44. Gallandat Huet RCG, Siemons AW, Baus D, van Rooyen-Butijn WT Haagenaars JA, van Oeveren W, Bepperling F: A novel hydroxyethyl starch (Voluven) for effective perioperative plasma volume substitution in cardiac surgery. Can J Anaesth 2000, 47:1207-15.

45. Cittanova ML, LeBlanc I, Legendre C, Mouquet C, Riou B, Coriat P: Effects of hydroxyethyl starch in brain-dead kidney donors on renal function in kidney-transplant recipients. Lancet 1996, 348:1620-2.

46. Legendre $\mathrm{C}$, Thervet $\mathrm{E}$, Page B, Percheron A, Noel LH, Kreis $\mathrm{H}$ : Hydroxyethylstarch and osmotic-nephrosis-like lesions in kidney transplantation. Lancet 1993, 342:248-49.

47. Brunkhorst FM, Englel C, Bloos F, Meier-Hellmann A, Ragaller M, Weiler N, Moerer O, Gruendling M, Oppert M, Grond S, Olthoff D, Jaschinski U, John S, Rossaint R, Welte T, Schaefer M, Kern P, Kuhnt E, Kiehntopf M, Hartog C, Natanson C, Loeffler M, Reinhart K, German competence network sepsis (SepNet): Intensive insulin therapy and pentastarch resuscitation in severe sepsis. N Engl J Med 2008, 358:125-39. 
48. Chinitz JL, Kim KE, Onesti G, Swartz C: Pathophysiology and prevention of dextran-40- induced anuria. J Lab Clin Med 1971, 77:76-87.

49. Moran M, Kapsner C: Acute renal failure associated with elevated plasma oncotic pressure. N Engl J Med 1987, 317:150-3.

50. Neff TA, Doelberg M, Jungheinrich C, Sauerland A, Spahn DR, Stocker R: Repetitive large-dose infusion of the novel hydroxyethyl starch 130/0,4 in patients with severe head injury. Anesth Analg 2003, 96:1453-9.

51. Sakr Y, Payen D, Reinhart K, Sipmann FS, Zavala E, Bewley J, Marx G, Vincent $J$ : Effects of hydroxyethyl starch administration on renal function in critically ill patients. Br J Anaesth 2007, 98:216-24.

52. Nohé B, Johannes T, Reutershan J, Rothmund A, Haeberle HA, Ploppa A, Schroeder $\mathrm{TH}$, Dieterich HJ: Synthetic colloids attenuate leukocyteendothelial interactions by inhibition of integrin function. Anesthesiology 2005, 103:759-67.

53. Feng X, Yan W, Wang Z, Liu J, Yu M, Zhu S, Xu J: Hydroxyethyl starch, but not modified fluid gelatin, affects inflammatory response in a rat model of polymicrobial sepsis with capillary leakage. Anesth Analg 2007, 104:624-30.

54. Wang P, Li Y, Li J: Hydroxyethyl starch 130/0.4 prevents the early pulmonary inflammatory response and oxidative stress after hemorrhagic shock and resuscitation in rats. Int Immunopharmacol 2009, 9:347-53.

55. Shoemaker WC, Appel PL, Kram HR: Tissue oxygen debt as a determinant of lethal and non-lethal postoperative organ failure. Crit Care Med 1988, 16:1117-20.

56. Grocott MP, Mythen MG, Gan TJ: Perioperative fluid management and clinical outcomes in adults. Anesth Analg 2005, 100:1093-106.

57. Hachenberg T, Grundling M: Acute failure of the intestinal barrier pathophysiology, diagnosis, prophylaxis and therapy. Anaesthesiol Reanim 1999, 24:4-12

58. Holte K, Sharrock NE, Kehlet H: Pathophysiology and clinical implications of perioperative fluid excess. Br J Anaesth 2002, 89:622-32.

59. Maerz L, Kaplan LJ: Abdominal compartment syndrome. Crit Care Med 2008, 36:S212-5.

60. Gottrup F, Firmin R, Rabkin J, Halliday BJ, Hunt TK: Directly measured tissue oxygen tension and arterial oxygen tension assess tissue perfusion. Crit Care Med 1987, 15:1030-6.

61. Perz S, Uhlig T, Kohl M, Bredle DL, Reinhart K, Bauer M, Kortgen A: Low and "supranormal" central venous oxygen saturation and markers of tissue hypoxia in cardiac surgery patients: a prospective observational study. Intensive Care Med 2011, 37:52-9.

62. Maddirala S, Khan A: Optimizing hemodynamic support in septic shock using central and mixed venous oxygen saturation. Crit Care Clin 2010, 26:323-33.

63. Bakker J, Schieveld SJ, Brinkert W: Serum lactate level as a indicator oft tissue hypoxia in severely ill patients. Ned Tijdschr Geneeskd 2000, 144:737-41.

64. Englehart MS, Schreiber MA: Measurement of acid-base resuscitation endpoints: lactate, base deficit, bicarbonate or what? Curr Opin Crit Care 2006, 12:569-74

65. Pinsky MR: Hemodynamic evaluation and monitoring in the ICU. Chest 2007, 132:2020-9.

66. Kastrup M, Markewitz A, Spies C, Carl M, Erb J, Grosse J, Schirmer U: Current practice of hemodynamic monitoring and vasopressor and inotropic therapy in post-operative cardiac surgery patients in Germany: results from a postal survey. Acta Anaesthesiol Scand 2007, 51:347-58.

67. LeDoux D, Astix ME, Carpati CM, Rackow EC: Effects of perfusion pressure on tissue perfusion in septic shock. Crit Care Med 2000, 28:2729-32.

68. Partrick DA, Bensard DD, Janik JS, Karrer FM: Is hypotension a reliable indicator of blood loss from traumatic injury in children? Am J Surg 2002, 184:555-9.

69. Hamilton-Davies C, Mythen MG, Salomon JB, Jacobson D, Shukla A, Webb AR: Comparison of commonly used clinical indicators of hypovolemia with gastrointestinal tonometry. Crit Care 1997, 23:276-81.

70. Webb AR: Recognizing hypovolaemia. Minerva Anestesiol 2001, 67:185-9.

71. Schachtrupp A, Graf J, Tons C, Hoer J, Fackeldey V, Schumpelick V: Intravascular volume depletion in a 24-hour porcine model of intraabdominal hypertension. J Trauma 2003, 55:734-40.

72. Marik PE, Baram M, Vahid B: Does central venous pressure predict fluid responsiveness? A systematic review of the literature and the tale of seven mares. Chest 2008, 134:172-8.
73. Reuter DA, Huang C, Edrich T, Shernan SK, Eltzschig HK: Cardiac output monitoring using indicator-dilution techniques: basics, limits, and perspectives. Anesth Analg 2010, 110:799-811.

74. Alhashemi JA, Cecconi M, della Rocca G, Cannesson M, Hofer CK: Minimally invasive monitoring of cardiac output in the cardiac surgery intensive care unit. Curr Heart Fail Rep 2010, 7:116-24.

75. Marx G, Cope T, McCrossan L, Swaraj S, Cowan C, Mostafa SM, Wenstone R, Leuwer M: Assessing fluid responsiveness by stroke volume variation in mechanically ventilated patients with severe sepsis. Eur J Anaesthesiol 2004, 21:132-8

76. Reuter DA, Goepfert MS, Goresch T, Schmoeckel M, Kilger E, Goetz AE: Assessing fluid responsiveness during open chest conditions. $\mathrm{Br} J$ Anaesth 2005, 94:318-23.

77. Sakka SG, Ruhl CC, Pfeiffer UJ, Beale R, McLuckie A, Reinhart K, MeierHellmann A: Assessment of cardiac preload and extravascular lung water by single transpulmonary thermodilution. Intensive Care Med 2000, 26:180-7.

78. Sander M, Spies CD, Berger K, Grubitzsch H, Foer A, Kramer M, Carl M, von Heymann C: Prediction of volume response under open-chest conditions during coronary artery bypass surgery. Crit Care 2007, 11:R121.

79. Brandstrup B, Tonnesen H, Beier-Holgersen R, Hjortso E, Ording H, LondorffLarsen K, Rasmussen MS, Lanng C, Wallin L, Iversen LH, Gramkow CS, Okholm M, Blemmer T, Svendsen PE, Rottensten HH, Thage B, Riis J, Jeppesen IS, Teilum D, Christensen AM, Graungaard B, Pott F, Danish Study Group on Perioperative Fluid Therapy: Effects of intravenous fluid restriction on postoperative complications: comparison of two perioperative fluid regimens: a randomized assessor-blinded multicenter trial. Ann Surg 2003, 238:641-8.

80. Holte K, Klarskov B, Christensen DS, Lund C, Nielsen KG, Bie P, Kehlet H: Liberal versus restrictive fluid administration to improve recovery after laparoscopic cholecystektomy: a randomized, double-blind study. Ann Surg 2004, 240:892-9.

81. Maharaj Ch, Kallam SR, Malik A, Hassett P, Grady D, Laffey JG: Preoperative intravenous fluid therapy decreases postoperative nausea and pain in high risk patients. Anesth Analg 2005, 100:675-82.

82. Nisanevich V, Felsenstein I, Almogy G, Weissmann C, Einav S, Matot I: Effect of intraoperative fluid management on outcome after intraabdominal surgery. Anesthesiology 2005, 103:25-32.

83. Rivers E, Nguyen B, Havstad S, Ressler J, Muzzin A, Knoblich B, Peterson E, Tomlanovich E: Early Goal-Directed Therapy In The Treatment Of Severe Sepsis And Septic Shock. N Engl J Med 2001, 345:1368-77.

84. Walsh SR, Tang T, Bass S, Gaunt ME: Doppler-guided intra-operative fluid management during major abdominal surgery: systematic review and meta-analysis. Int J Clin Pract 2008, 62:466-70.

85. Noblett SE, Snowden CP, Shenton BK, Horgan AF: Randomized clinical trial assessing the effect of Doppler-optimized fluid management on outcome after elective colorectal resection. Br J Surg 2006, 93:1069-76.

86. Goepfert MSG, Reuter DA, Akyol D, Lamm P, Kilger E, Goetz AE: Goaldirected fluid management reduces vasopressor and catecholamine use in cardiac surgery patients. Intensiv Care Med 2007, 33:96-103.

87. Sakka SG, Klein M, Reinhart K, Meier-Hellmann A: Prognostic value of extravascular lung water in critically ill patients. Chest 2002, 122:2080-6.

88. Rivers EP, Coba V, Whitmill M: Early goal-directed therapy in severe sepsis and septic shock: a contemporary review of literature. Curr Opin Anesthesiol 2008, 21:128-40.

89. Hamilton MA, Cecconi M, Rhodes A: A systematic review and metaanalysis on the use of pre-emptive hemodynamic intervention to improve postoperative outcomes in moderate and high-risk surgical patients. Anesth Analg 2010.

90. Giglio MT, Marucci M, Testini M, Brienza N: Goal-directed haemodynamic therapy and gastrointestinal complications in major surgery: a metaanalysis of randomized controlled trials. Br J Anaesth 2009, 103:637-46.

doi:10.1186/2110-5820-1-2

Cite this article as: Strunden et al:: Perioperative fluid and volume management: physiological basis, tools and strategies. Annals of Intensive Care 2011 1:2. 